\title{
Analisis Peramalan Jumlah Penderita Hipertensi Pada Lansia Di Kabupaten Malang Menggunakan Metode Arima Box-Jenkins
}

\section{Analysis Forecasting Number Of Hypertension Patients In Elderly In Malang District Using Arima Box-Jenkins Method}

\author{
Nanta Sigit ${ }^{1)}$ \\ Arief Setiyoargo ${ }^{2)}$ \\ 1,2) D-IV Manajemen Informasi Kesehatan, STIKes Panti Waluya Malang \\ E-mail:nantasigit1991@gmail.com
}

\begin{abstract}
Hypertension is a medical condition where people whose blood pressure rises above normal is $140 / 90 \mathrm{mmHg}$ and hypertension can run the risk of morbidity and even death. In order to make plans to reduce the number of people with hypertension in the regions with the principle of effective and responsible, a valid forecast forecast is needed. The relatively large difference between the target and achievements in overcoming hyperteni sufferers in Malang Regency during 2014 - 2019, and given the importance of forecasting as an indicator of reducing hypertension sufferers, it is deemed necessary to conduct research on the application of the Box-Jenkins model in forecasting hypertension sufferers. This study aims to make an estimated model of hypertension sufferers in Malang district by using data from the health office from 2014 to 2019.

The analysis technique applied is the Box-Jenkins or Autoregressive Integreted Moving Average (ARIMA) model. The results showed that by using data from the Malang district health office from 2014 to 2019, it was concluded that the best forecasting model was ARIMA $(1,0,1)$. Researchers hope that forecasting methods and forecasting results can be used as additional information for the health department in Malang district in determining policies to be taken in the prevention of hypertension patients according to the needs of patients in Malang district.
\end{abstract}

Keywords: Hypertension in the elderly; Jenkins ARIMA Box Model

\begin{abstract}
Abstrak
Hipertensi merupakan sebuah kondisi medis dimana orang yang tekanan darah meningkat diatas normal yaitu 140/90 $\mathrm{mmHg}$ dan hipertensi dapat mengalami resiko kesakitan (morbiditas) bahkan kematian (mortalitas). Dalam rangka membuat perencanaan menurunkan jumlah penderita hipertensi di daerah dengan prinsip efektif dan bertanggung jawab diperlukan perkiraan peramalan yang valid. Adanya selisih yang relatif cukup besar antara target dan capaian dalam menanggulangi penderita hiperteni Kabupaten Malang selama tahun 2014 - 2019, dan mengingat pentingnya peramalan sebagai indikator menurunkan penderita hipertensi, maka dipandang perlu melakukan penelitian mengenai penerapan model Box-Jenkins dalam peramalan penderita hipertensi. Penelitian ini bertujuan untuk membuat model estimasi penderita hipertensi kabupaten malang dengan mengunakan data dinkes dari tahun 2014 sampai dengan tahun 2019.

Teknik analisis yang diterapkan adalah model Box-Jenkins atau Autoregresive Integreted Moving Average (ARIMA). Hasil penelitian menunjukkan bahwa dengan menggunakan data dinas kesehatan kabupaten malang tahun 2014 sampai dengan tahun 2019, disimpulkan bahwa model peramalan yang terbaik adalah dengan ARIMA $(1,0,1)$. Peneliti berharap metode peramalan dan hasil peramalan tersebut dapat digunakan sebagai tambahan informasi bagi pihak dinas kesehatan di kabupaten malang dalam menentukan kebijakan yang harus diambil dalam pencegahan penderita hipertensi sesuai kebutuhan pasien di kabupaten Malang.
\end{abstract}

Kata kunci: Hipertensi pada lansia; Model ARIMA Box Jenkins 


\section{Pendahuluan}

Pembangunan kesehatan di Indonesia merupakan upaya kesehatan untuk mencapai kemampuan hidup sehat bagi setiap penduduk dalam mewujudkan derajat kesehatan yang optimal. Keberhasilan pemerintah dalam pembangunan nasional, telah terwujud hasil yang positif diberbagai bidang, yaitu adanya kemajuan ekonomi, perbaikan lingkungan hidup, kemajuan ilmu pengetahuan dan teknologi, terutama di bidang medis sehingga dapat meningkatkan kualitas kesehatan penduduk serta meningkatkan Usia Harapan Hidup (UHH). Akibatnya jumlah penduduk yang berusia lanjut cenderung meningkat dan bertambah lebih cepat.

Penduduk lansia di Indonesia pada tahun 1980 hanya 7,9 juta orang $(5,45 \%)$ dari jumlah penduduk di Indonesia dengan UHH 52,2 tahun. Namun, pada tahun 2006 angka meningkat hingga dua kali lipat menjadi 19 juta orang $(8,9 \%)$ dari jumlah penduduk di Indonesia dengan $\mathrm{UHH} 66,2$ tahun dan diperkirakan tahun 2020 mencapai 28,8 juta orang $(11,34 \%)$ dari jumlah penduduk di Indonesia dengan UHH 71,1 tahun.

Hipertensi atau tekanan darah tinggi merupakan sebuah kondisi medis dimana orang yang tekanan darahnya meningkat diatas normal yaitu $140 / 90 \mathrm{mmHg}$ dan dapat mengalami resiko kesakitan (morbiditas) bahkan kematian (mortalitas). Penyakit ini sering dikatakan sebagai the silent diseases. Faktor resiko hipertensi dibagi menjadi 2 golongan yaitu hipertensi yang tidak bisa diubah dan hipertensi yang dapat diubah. Hipertensi yang dapat diubah meliputi merokok, obesitas, gaya hidup yang monoton dan stres. Hipertensi yang tidak dapat dirubah meliputi usia, jenis kelamin, suku bangsa, faktor keturunan (Rusdi \& Isnawati, 2009).

Hipertensi pada lansia di Amerika mempunyai prevalensi yang tinggi pada usia 65 tahun didapatkan $60-80 \%$ atau sekitar lima puluh juta warga lansia
Amerika mempunyai prevalensi tinggi untuk hipertensi (Rusdi \& Isnawati, 2009). Menurut Depkes (2006) pada golongan umur 55-64 tahun, penderita hipertensi pada pria dan wanita sama banyak. Dari beberapa penelitian tingginya prevalensi hipertensi sejalan dengan bertambahnya umur. Berdasarkan penelitian yang dilakukan di 6 kota besar seperti Jakarta, Padang, Bandung, Yogyakarta, Denpasar, dan Makasar terhadap usia lanjut (55-85), didapatkan prevalensi hipertensi sebesar 52,5\% (Sarasaty, 2011). Maka kali ini peneliti mencoba meramal penderita hipertensi di kab. malang menggunakan model ARIMA Box Jenkins. Peneliti berharap metode peramalan dan hasil peramalan tersebut dapat digunakan sebagai tambahan informasi dalam menurunkan penderita hipertensi di kabupaten malang.

\section{Metode penelitian}

Untuk meramalkan penderita hipertensi dalam kurun waktu yang cukup lama, yaitu dari dari tahun 2014 sampai dengan tahun 2019. Data bersumber dari Dinas Kesehatan Kabupaten Malang, yang selanjutnya dianalisis dengan menggunakan model BoxJenkins.

Box dan Jenkins mempopulerkan metode peramalan data univariat runtut waktu yang terdiri dari 3 tahap dalam memilih model yang cocok untuk melakukan estimasi dan peramalan. Peramalan (forecasting) dengan menggunakan data runtun waktu (time series) secara sederhana sering dilakukan dengan analisis trend. Namun agar hasil peramalan lebih akurat, terutama untuk data runtun waktu yang cukup panjang, maka data runtun waktu dapat dianalisis dengan mempertimbangkan berbagai perilaku data melalui berbagai model antara lain model autoregressive (AR), moving average (MA) dan autoregressive moving average (ARIMA) (Wei, 2011), yang dijelaskan sebagai berikut. 


\section{Hasil dan Pembahasan}

Dilakukan analisis terhadap metode yang digunakan, yaitu metode ARIMA pada data jumlah penderita hipertensi di kabupaten malang. Langkah-Langkah melakukan metode peramalan ARIMA BoxJenkins.

Jika kita lihat pada Time Series plot pada Gambar 1 dapat diketahui bahwa pola data pada data penderita hipertensi belum stasioner dalam varian tetapi belum stasioner dalam mean.

Dari Gambar 2, menunjukkan bahwa nilai lamda -2, hal ini stasioner dalam varian tidak terpenuhi dan dilakukan uji transformasi varian yang ke-1. Didapatkan hasil pada Gambar 3 dibawah ini.

Dari Gambar 3 menunjukkan nilai lamda sebesar 1. Hal ini dapat ditarik kesimpulan stasioner dalam varian apabila lamda sebesar 1. Stasioner dalam varian sudah terpenuhi dan dilanjukan kedalam uji stasioner dalam mean.

Untuk bisa memastikan data stasioner dalam varian dapat dilihat pada Gambar 3. Pada uji yang dilakukan di Gambar 3 dengan menggunakan transformasi Box Cox, dari transformasi tersebut diperoleh nilai $\lambda$ sebesar 1 yang menunjukkan bahwa varian stabil. Sebaliknya, untuk melihat data stasioner dalam rata - rata dapat dilihat dari Gambar 4 plot ACF penderita hipertensi dan Gambar 5 plot $P A C F$ penderita hipertensi. Berdasarkan identifikasi diatas maka pendugaan model untuk penderita hipertensi kabupaten malang yaitu ARIMA $(0,0,1)$, ARIMA $(1,0,0)$, ARIMA $(1,0,1)$.

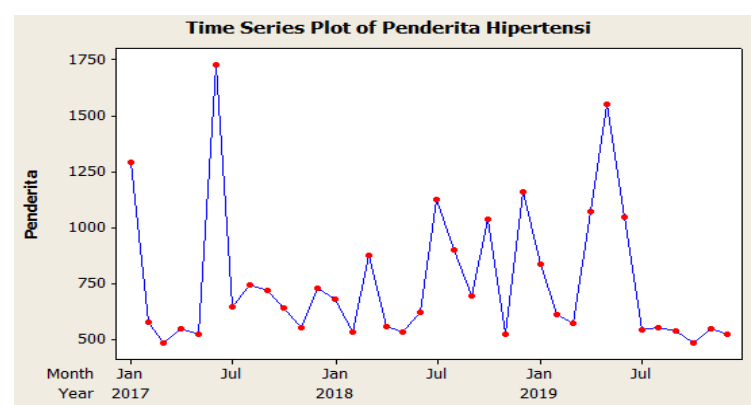

Gambar 1. Time Series Plot Penderita Hipertensi Kab.Malang

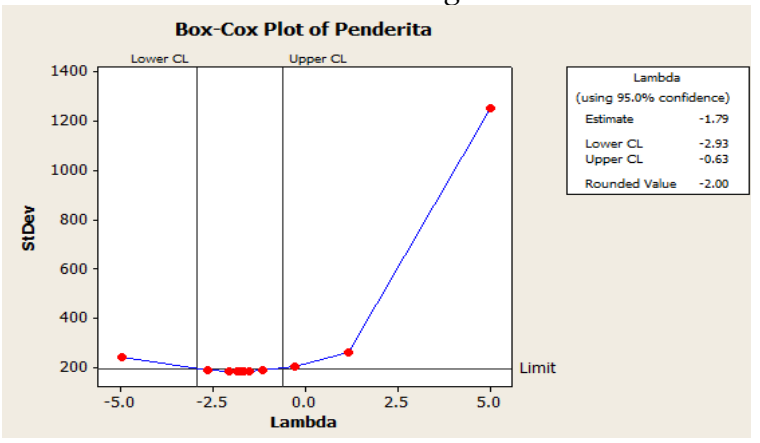

Gambar 2. Transformasi Box-Cox Penderita Hipertensi

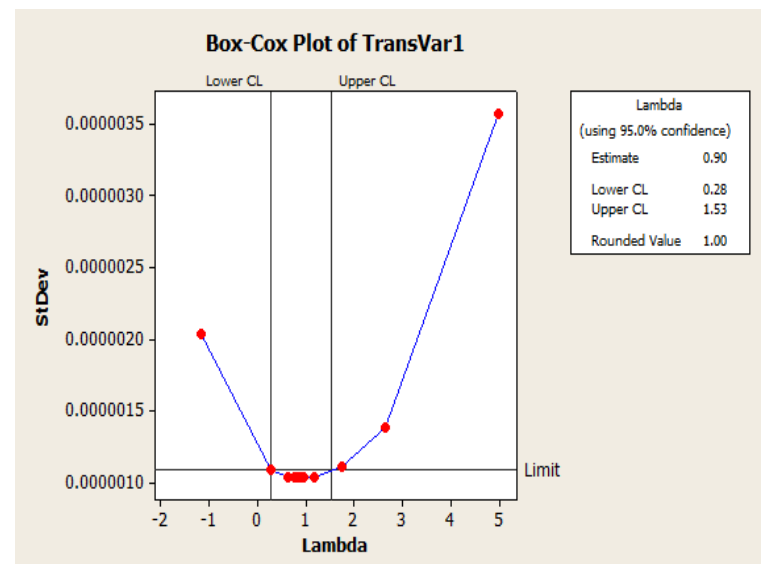

Gambar 3. Transformasi Box-Cox penderita hipertensi

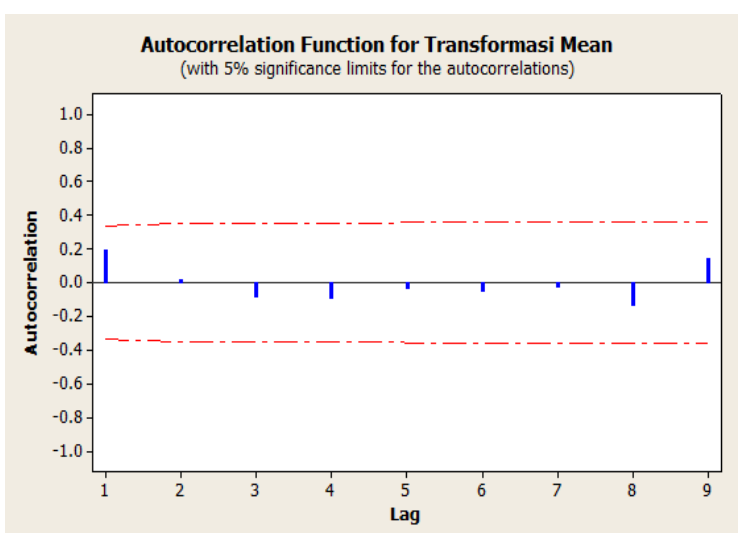

Gambar 4. Plot Autocorrelation (ACF) Penderita Hipertensi 


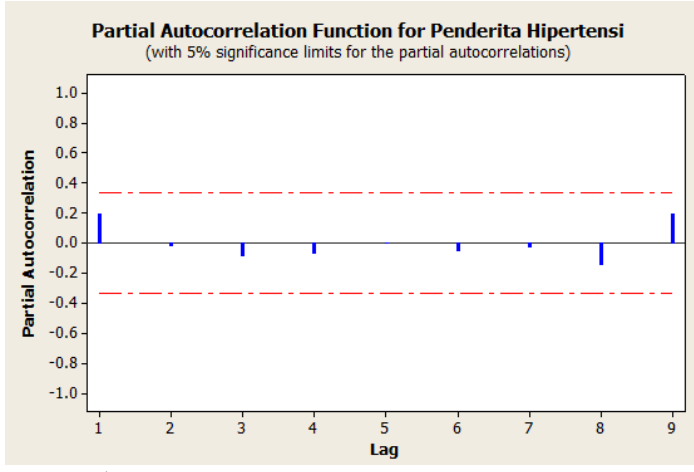

Gambar 5. Plot Partial Autocorrelation (PACF) penderita hipertensi

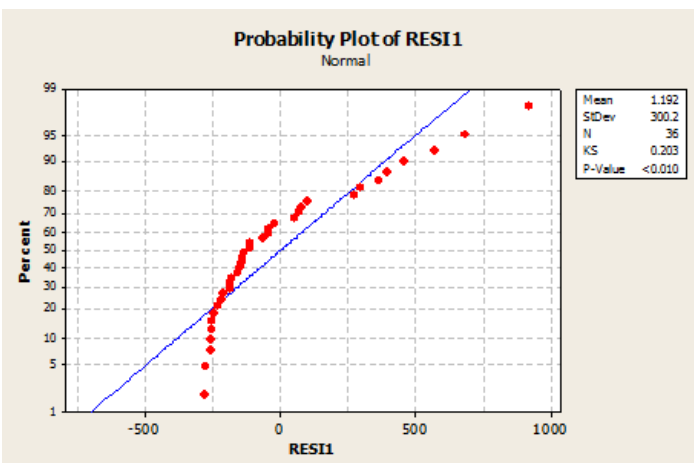

Gambar 6. Uji Kolmogorov Smirnov

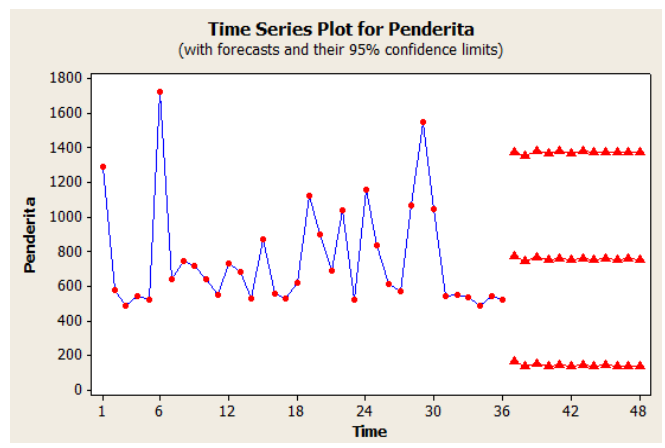

Gambar 7. Forecasting penderita hipertensi Kab Malang

Setelah dilakukan pendugaan awal model ARIMA dengan melihat plot ACF dan PACF maka dilakukan pengujian parameter. Pengujian parameter digunakan untuk menunjukkan apakah parameter sudah signifikan terhadap model atau layak untuk dijadikan model. Pengujian parameter dilakukan dengan menggunakan statistik uji t-student atau dengan membandingkan nilai p-value yang didapat dari output komputer dengan nilai a yang digunakan.

Dalam suatu pemodelan, seluruh
Tabel 1. Uji Signifikasi Model ARIMA Penderita Hipertensi

\begin{tabular}{llrl}
\hline ARIMA & Parameter & Pvalue & Keputusan \\
\hline \multirow{2}{*}{$(1,0,0)$} & AR(1) & 0.586 & Tidak \\
& & & Signifikan \\
$(0,0,1)$ & MA(1) & 0.507 & Signifikan \\
$(1,0,1)$ & AR(1) & 0.002 & Signifikan \\
& MA(1) & 0.000 & Signifikan \\
\hline
\end{tabular}

Tabel 2. Pemeriksaan White Noise pada Penderita Hipertensi

\begin{tabular}{rrrrl}
\hline ARIMA & \multicolumn{3}{c}{ Lag } & \multicolumn{1}{l}{ Ljung- } \\
\hline \multirow{2}{*}{$(1,0,1)$} & 12 & 6.4 & 0.699 & Terima $\mathrm{H}_{0}$ \\
& 24 & 22.4 & 0.376 & Terima $\mathrm{H}_{0}$ \\
\hline
\end{tabular}

Tabel 3. Hasil Ramalan Penjualan

\begin{tabular}{clc}
\hline Tahun & Bulan & Forecasting \\
\hline \multirow{6}{*}{2020} & Januari & 772 \\
& Februari & 746 \\
& Maret & 767 \\
& April & 750 \\
& Mei & 763 \\
& Juni & 753 \\
& Juli & 761 \\
& Agustus & 754 \\
& September & 760 \\
& Oktober & 755 \\
& November & 759 \\
& Desember & 756 \\
\hline
\end{tabular}

parameter yang digunakan harus signifikan. Berdasarkan pada Tabel 1 dapat dilihat bahwa nilai $\mathrm{p}$-value pada parameter dari model $\operatorname{ARIMA}(1,0,1)$ kurang dari a, sehingga berdasarkan $\mathrm{p}$-value, parameter model ARIMA $(1,0,1)$ tersebut adalah signifikan sehingga parameter pada model tersebut baik untuk digunakan.

Setelah selesai menaksir masing-masing parameter dari model ARIMA untuk data penderita hipertensi maka selanjutnya dilakukan pemeriksaan diagnostik dengan memeriksa residual apakah white noise 
berdistribusi normal. Hal ini bertujuan untuk membuktikan bahwa model ARIMA tersebut telah memadai. Pemeriksaan white noise apabila antara residualnya tidak terjadi korelasi sehingga pada residualnya tidak terdapat model.

Berdasarkan Tabel 2 tentang pengujian white noise untuk data penderita hipertensi model ARIMA yang sudah white noise nilai $P_{-}$value $>\alpha$. Berdasarkan uraian diatas, dapat disimpulkan bahwa berdasarkan uji kesesuaian model, model yang sesuai untuk digunakan pada data penderita hipertensi adalah ARIMA $(1,0,1)$.

Tahap selanjutnya setelah pemeriksaan asumsi white noise adalah melakukan pemeriksaan kenormalan residual pada masing- masing model ARIMA. Uji asumsi distribusi normal ini bertujuan untuk mengetahui apakah residual data telah memenuhi asumsi kenormalan atau belum. Untuk melakukan pemeriksaan ini digunakan Uji Kolmogorov Smirnov.

Pada data penderita hipertensi ketika dilakukan pemeriksaan terhadap kenormalan diketahui bahwa dengan melihat nilai $\mathrm{p}$-value residual dari model pada penderita hipertensi mengikuti distribusi normal. Hal ini dapat dilihat nilai p-value dari model ARIMA $(1,0,1)$ memiliki nilai lebih dari a yang digunakan yaitu $5 \%$, yaitu sebesar $>0,203$ sehingga keputusan yang diambil adalah gagal tolak H0, yaitu residual mengikuti distribusi normal.

Setelah didapatkan model terbaik dari data penderita hipertensi, maka dilakukan peramalan dengan menggunakan model yang didapatkan yaitu ARIMA $(1,0,1)$ pada data penderita hipertensi. Hasil peramalan jumlah pasien hipertensi ini untuk periode 12 bulan ke depan seperti yang dapat dilihat pada Tabel 3.

\section{Simpulan dan Saran}

\section{Simpulan}

Dari analisis dan pembahasan yang dilakukan pada bab sebelumnya maka dapat diambil beberapa kesimpulan berdasarkan tujuan penelitian yaitu:

Berdasarkan model ARIMA Box -
Jenkins pada penderita hipertensi pada tahun 2020 di Kabupaten Malang diperoleh nilai peramalan sebagai berikut : bulan Januari sebanyak 772 orang, Februari sebanyak 746 orang, Maret sebanyak 767 orang, April sebanyak 750 orang, Mei sebanyak 763 orang, Juni sebanyak 753 orang, Juli sebanyak 761 orang, Agustus sebanyak 754 orang, September sebanyak 760 orang, Oktober sebanyak 755 orang, November sebanyak 759 orang dan Desember sebanyak 756 orang.

\section{Saran}

Sebaiknya dalam pengambilan sampel data tidak terlalu sedikit sehingga didapatkan hasil peramalan yang tepat dan dapat memenuhi kriteria. Dalam penghitungan in sample dan out sample harus lebih teliti.

\section{Daftar Pustaka}

Arjatmo, T. H. (2001). Ilmu Penyakit Dalam. Jakarta: Balai Penerbit FKUI.

Azam, M. (2015). Peravalensi Hipertensi Berdasarkan Riwayat Hipertensi Dalam Keluarga. Jakarta: Erlangga.

Anggraini, F. (2011). Hubungan antara Gaya Hidup dengan Status Kesehatan Lansia Binaan Puskesmas Pekayon Jaya Bekasi (Skripsi). Jakarta: Fakultas Kedokteran Universitas Indonesia.

Bowerman, B.L. and O'Connell, R.T. (2011), Forecasting and Time Series: An Applied Approach, 3rd edition, Duxbury Press: USA.

Cryer, J.D. (2011). Time Series Analysis. Boston: PWS-Kent Publishing Company.

Daniel, W.W. (2012). Statistika Nonparametrik Terapan. Jakarta: PT. Gramedia.

Depkes. 2006. Pedoman Teknis Penemuan dan Tata Laksana Penyakit Hipertensi. Jakarta: Direktorat Pengendalian Penyakit Tidak Menular Depkes RI.

Douglas JG, B. G. (2013). Management of high BP in African Americans: Consensus statements of hypertention in African Americans Working Group of The International Society on Hypertention in Blacks. Arch Intern Med 163:525- 
241.

Effendi, Ferry dan Makhfudli. (2010). Keperawatan Kesehatan Komunitas: Teori dan Praktik Dalam Keperawatan. Jakarta: Salemba Medika.

Eka, W. (2017). Analisis Peramalan Banyaknya Permintaan Darah Di Surabaya Menggunakan Metode Arima BoxJenkins. Dipl. III Statistika FMIPA. Surabaya, ITS.

Gujarati, D. (2011). Basic Econometrics, Mc Grow-Hill.Inc, New York.

Kurniawan, R. (2009). Identifikasi Drug Related Problems (DRPs) Potensial Kategori Interaksi Obat pada Pasien Hipertensi Geriatri di Instalasi Rawat Inap Rumah Sakit PKU Muhammadiyah Surakarta (Skripsi). Surakarta: Fakultas Farmasi Universitas Muhammadiyah Surakarta.

Lanny, Sustrani dkk;. (2004). Informasi lengkap untuk penderita hipertensi. Jakarta: Gramedia Pustaka Utama.

Rusdi dan Isnawati, N. (2009). Awas, Anda Bisa Mati Cepat Akibat Hipertensi \& Diabetes. Yogyakarta : Diva Press

Sani, A. (2008). Hypertension; Current Perspective. Jakarta: Medya Crea.
Sarasaty, RF. (2011). Faktor-faktor yang Berhubungan dengan Hipertensi pada Kelompok Lanjut Usia di Kelurahan Sawah Baru Kecamatan Ciputat, Kota Tangerang Selatan (Skripsi). Universitas Islam Negeri Syarif Hidayatullah Jakarta. Jakarta.

Shimamoto. (2016). Chinese Hypertension Society. New York: Delmar Publisher Inc.

Mancia, G. (2017). Assessment of Long-term Antihypertensive Treatment by Clinic Anambulatory Blood Pressure. Data from the ELSA Study. J Hypertensi.

Smith, T. (2011). Tekanan Darah Tinggi. Jakarta: Arcan.

Makridakis, W., Mc Gee. (2013), Metode dan Aplikasi Peramalan, Edisi kedua, Bina Rupa Aksara, Jakarta.

Yunus, P. K. (2009). Analisis Time Series Pada Penjualan Shampo Switzal Di Daerah Jakarta Dan Jawa Barat. Dipl. III Statistika FMIPA. Surabaya, ITS.

Wei, W., W. S., (2011), Time Analysis Univariate and Multivariate Methods, Addison Wesley Publishing Company, Inc, America. 